\title{
Editorial Comment: Cardiovascular Morbidity in a Randomized Trial Comparing GnRH Agonist and GnRH Antagonist among Patients with Advanced Prostate Cancer and Preexisting Cardiovascular Disease
}

Margel $D^{1,2}$, Peer $A^{3}$, Ber $Y^{1}$, Shavit-Grievink $L^{1,4}$, Tabachnik T ${ }^{1}$, Sela $S^{1}$, et al.

1 Division of Urology, Rabin Medical Center, Petach Tikva, Israel; ${ }^{2}$ Sackler Faculty of Medicine, Tel Aviv University, Tel Aviv, Israel; ${ }^{3}$ Department of Oncology, Rambam Health Care Campus and Rappaport Faculty of Medicine, Technion-Israel Institute of Technology, Haifa, Israel; ${ }^{4}$ Davidoff Cancer Centre, Rabin Medical Center, Petach Tikva, Israel

J Urol. 2019 Dec;202(6):1199-1208.

DOI: 10.1097/JU.0000000000000384 | ACCESS: 10.1097/JU.0000000000000384

Felipe Lott ${ }^{1}$

${ }^{1}$ Instituto Nacional do Câncer - INCA, Rio de Janeiro, RJ, Brasil

\section{COMMENT}

Retrospective studies have shown an association between androgen deprivation therapy (ADT) and an increase risk of cardiovascular disease (CVD) $(1,2)$.

This paper is the first randomized study (phase II) on cardiovascular morbidity with high risk or metastatic prostate cancer patients with previous CVD events (CVDes) (37\% experienced a myocardial infarction within a year before randomization) and treated with GnRh agonist (with 2 times more diabetes patients) or GnRh antagonist by one year period time.

The primary endpoint was to compare endothelial function using the EndoPAT 2000 device (3) that appears to predict cardiovascular outcomes (4). The secondary endpoint was CVDes.

There was no difference in the primary endpoint between the 2 groups but it occurred in the secondary one (more subject to statistical error) with 3\% of major cardiovascular and cerebrovascular event in the GnRh antagonist group and 20\% in the GnRh agonist one ( $\mathrm{p}=0.013)$.

Maybe it is not appropriate to compare arms of a phase II trial especially in this small one. A large phase III trial (PRONOUNCE study) may define it better but, until now, an alert has been sent in patients with preexisting CVD (especially with a new event in the last 12 months). 


\section{CONFLICT OF INTEREST}

None declared.

\section{REFERENCES}

1. Hu JC, Williams SB, O'Malley AJ, Smith MR, Nguyen PL, Keating NL. Androgen-deprivation therapy for nonmetastatic prostate cancer is associated with an increased risk of peripheral arterial disease and venous thromboembolism. Eur Urol. 2012;61:1119-28.

2. Jespersen CG, Nørgaard M, Borre M. Androgen-deprivation therapy in treatment of prostate cancer and risk of myocardial infarction and stroke: a nationwide Danish population-based cohort study. Eur Urol. 2014;65:704-9.

\section{Felipe Lott, MD}

3. McCrea CE, Skulas-Ray AC, Chow M, West SG. Test-retest reliability of pulse amplitude tonometry measures of vascular endothelial function: implications for clinical trial design. Vasc Med. 2012;17:29-36.

4. Rubinshtein R, Kuvin JT, Soffler M, Lennon RJ, Lavi S, Nelson $\mathrm{RE}$, et al. Assessment of endothelial function by non-invasive peripheral arterial tonometry predicts late cardiovascular adverse events. Eur Heart J. 2010;31:1142-8.

ARTICLE INFO

(iD) Felipe Lott

Instituto Nacional do Câncer - INCA

Rio de Janeiro, RJ, Brasil

E-mail:felipelott@hotmail.com

Int Braz J Urol. 2020; 46: 853-4 